\title{
Stereochemistry of Carbon Nanotubes for Electronic Applications
}

\author{
Michael A. Wilson, Craig P. Marshall, Adam Moy and G.S Kamali Kannangara. \\ Department of Chemistry, Materials and Forensic Science, University of Technology, Sydney \\ PO Box 123, Broadway, Sydney 2007, Australia
}

Keywords: carbon nanotubes, stereochemistry, additives, plasma arcing, ball milling

\begin{abstract}
Results are presented from studies to prepare carbon nanotubes of single geometry.

Carbon nanotubes of certain stereochemistry have been found to be conductive. Others have been found to be excellent transistors, and together nanoelectronic devices have already been formed from them including logic gate circuits. Two synthetic approaches have been tried, namely plasma arcing in the presence of additives and ball milling. In plasma arcing, cathode deposits are altered by the presence of naphthalene in the feed material. The mixture of nanotubes so formed has a larger average void size than that formed in the absence of naphthalene. The results support proposed mechanisms of nanotube formation which involve growth by incorporation of carbon atoms into open tubes. They also show that naphthalene can be directly incorporated into fullerene black and thereby increase the number of hexagonal sheet structures in the carbon deposit. Work so far in ball milling has been confined to studies of the destruction of graphite crystalline phases.
\end{abstract}

\section{INTRODUCTION}

Carbon nanotubes are related to fullerenes ("buckyballs") the spherical and oval shaped molecules of carbon atoms discovered in the mid to late 1980's and the subject of a recent Nobel prize. Carbon nanotubes are cylindrical sheets of graphite with diameters of only a few nanometers across but a few thousand nanometers in length, and preferably longer. Discovered in 1991 by Sumio Iijima ${ }^{1}$ the tubular structure are a macromolecule of carbon, analogous to a sheet of chicken wire, which is similar to a network of hexagonal rings of carbon. In conventional graphite molecular sheets of graphite lay stacked on top of one another, but they slide past each other easily imparting its lubricant and dispersive properties. However, if coiled only the tangents of the graphitic planes become in contact and hence the properties are more like those of a molecular solid. A nanotube may consist of one tube of graphite (and hence called a single walled nanotube, SWNT) or a number of concentric tubes (and hence called multiwalled nanotube, MWNT). Different single walled nanotubes can exist because the graphitic sheet can roll up in different ways (Figures 1-3). This is not just to form tubes with different diameters but also tubes with different orientations of graphitic planes brought about by displacement of the hexagonal rings. The conventional way to describe this is by looking at the unrolled sheet and expressing the rolling process by vectors $(n, m)$, where $n$ and $m$ are integers of the vector equation $R=n a_{1}+m_{2}$. In order to express the structure of nanotubes in a quick and non pictorial way, the nanotube geometry is described by the vectors $\mathrm{a}_{1}, \mathrm{a}_{2}$. Zig zag 


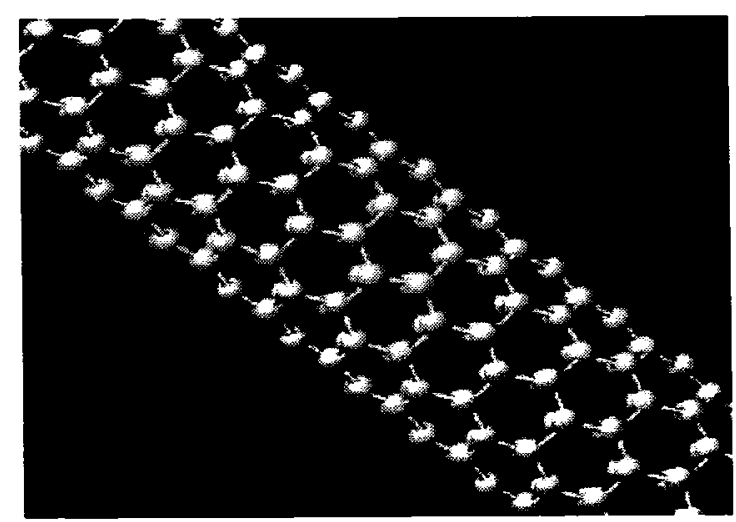

Fig. 1: Armchair $(5,5)$ nanotube

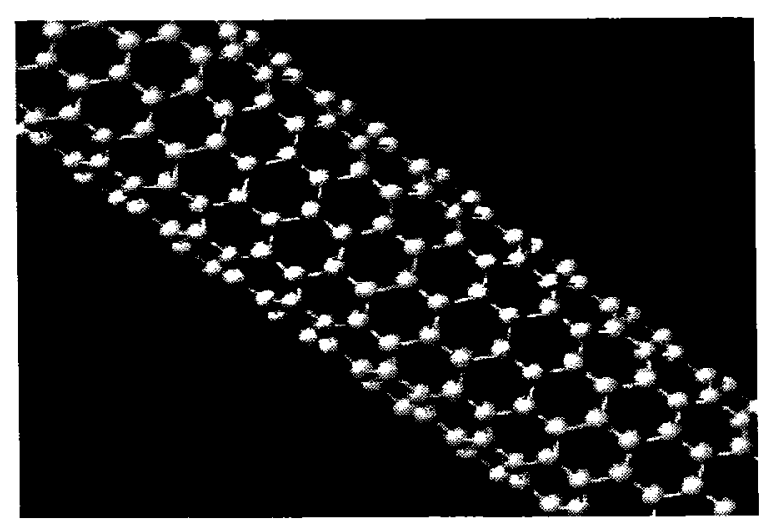

Fig. 2: Zig-Zag $(10,0)$ nanotube

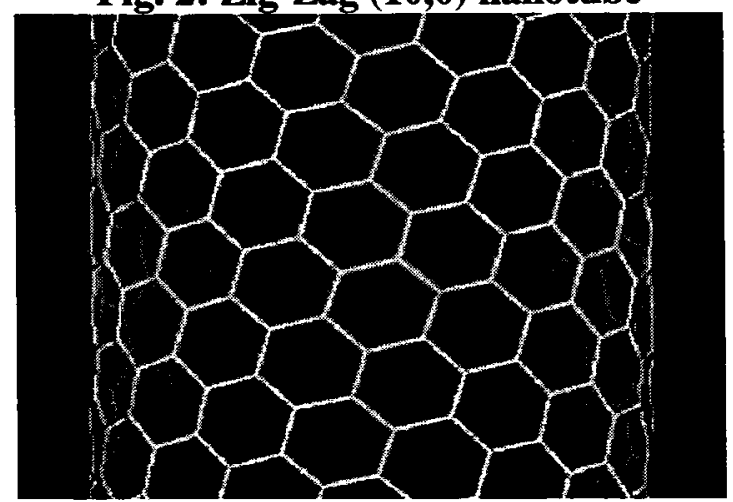

Fig. 3: Chiral $(14,5)$ nanotube

nanotubes have configurations 9,$0 ; 10,0 ; 11,0$ etc since one vector is arbitrarily placed as zero. Armchair nanotubes have na $a_{1}$ and $\mathrm{ma}_{2}$ equal and hence configurations 5,5: 6,6: 7,7 etc depending on width of nanotube because the vectors must be the same to bring $R$ over the armchair line. The two vectors $a_{2}, a_{1}$ can have a variety of different locations and magnitudes in other tubes.

The structure of the nanotube affects its properties including conductance, density, and lattice ure. For example, a SWNT is metallic if the value $\mathrm{n}-\mathrm{m}$ is divisible by three. Consequently, 
when tubes are formed with random values of $\mathrm{n}$ and $\mathrm{m}$, we would expect that two-thirds of nanotubes would be semi-conducting, the other third metallic. To maximise potential applications clearly, the aim of current preparative carbon nanotube research should be directed to producing nanotubes of a single type and configuration e.g. 5,5 or $10,014,5$ etc.

One process by which nanotubes are formed, namely plasma arcing, was used by Iijima ${ }^{1}$ to produce the first nanotubes. The technique uses an arc generator to generate gram quantities of soot from a graphite anode and nanotubes deposit on the cathode. Direct currents of 100-200 A and voltages of 10-20 V are used. Our group was the first to identify and then prepare fullerenes and nanotubes from a molecular solid, namely coal, rather than graphite which is an expensive lattice solid. This was achieved first by laser pyrolysis ${ }^{2}$ and then by plasma arcing using the coal as an anode ${ }^{3}$. Our work has subsequently been verified by others ${ }^{47}$. The prime chemical advantage of the coal versus the graphite process other than cost is in the mechanism of fullerene and nanotube formation. Whereas, the graphite process has to proceed through single atoms formed in the plasma (C1 carbon units), larger entities such as small ring aromatics are involved in the coal process 8 because the weak links between small aryl structures in coal yield aromatic species which can be directly incorporated into fullerenes and nanotubes. That is, all bonds in the processed material do not have to be broken during arcing. We have recent confirmation of this mechanism from plasma arcing experiments using naphthalene as fill in hollow graphite tubes in order to simulate the way fullerenes and nanotubes might be formed from polycyclic hydrocarbons in coal ${ }^{9,10}$. The results show that naphthalene in the plasma arc fringe increases the $\mathrm{C} 70$ to $\mathrm{C} 60$ fullerene ratio in the product soot and also increases the void space in the formed multiwalled nanotubes. The most probable explanation is that naphthalene is more readily incorporated into this structure because two aromatic rings together can be accommodated in $\mathrm{C} 70$ but not $\mathrm{C} 60$ fullerene. $\mathrm{C} 60$ fullerene may incorporate naphthalene, but only after a six to five membered ring rearrangement. Similar arguments are valid to describe why the caps in nanotubes are larger and hence the void space bigger. This work is testament to the fact that nanotubes and fullerenes can be formed in cooler parts of the arc where molecular entities can survive. They could certainly not survive in the centre of the arc which reaches $2000^{\circ} \mathrm{C}$.

Fullerenes have been prepared from naphthalene and some exotic compounds by thermal processes not involving arcing ${ }^{11}$ so there is clear evidence that single atomic units do not always have to be involved. We have also prepared fullerenes from mesophase ${ }^{12}$ and from the pyrolysis residue of kerogen isolated from oil shale ${ }^{13-15}$. Single walled rather than multiwalled nanotubes can be formed by adding cobalt and other metals to the electrodes ${ }^{16}$. This process also works for coal, and iron in coal can assist ${ }^{17}$.

Despite our and other pioneering work, it is fair to say that it is now clear there are better methods of preparing nanotubes. Laser ablation ${ }^{18-22}$ of carbon containing a small percentage of a metal catalyst such as cobalt, pioneered by Professor Smalley at Rice University, has produced the purest SWNTs. This method utilises a laser to impinge on a heated (usually $1500 \mathrm{~K}$ ) composite graphitemetal ( $\mathrm{Ni}, \mathrm{Co}$ or $\mathrm{Fe}$ ) target under an atmosphere of inert gas (argon) in a flow tube. The carbon vapourises and the nanotubes self assemble from the carbon vapour in the presence of the metal catalysts and then condense on the cooler walls of the flow tube. The collected material contains up to $80 \%$ nanotubes by weight and consists of bundles or ropes of SWNT in near close packed order. The yield depends on the amount and type of catalysts, laser power and wavelength, temperature, pressure and type of buffer gas, and geometry of the fluid flow near the carbon target. The best 
results were obtained by operating with two successive laser pulses (532 nm and $1064 \mathrm{~nm}$ separated by $50 \mathrm{~ns}$ ), in an atmospheric of $66.7 \mathrm{kPa}$ argon with $1 \% \mathrm{Ni}$ or Co added as a catalyst.

In addition, there has been a major effort to put carbon nanotubes on surfaces for example, glass $^{23}$, nanolithographic templates ${ }^{24}$, gold ${ }^{25}$ and patterned catalytic substrates ${ }^{26}$. More recently carbon nanotubes have been made by other methods ${ }^{27-32}$ including catalytic chemical vapour deposition (CCVD) of various gases ${ }^{33}$ sometimes involving laser ablation ${ }^{34,35}$.

Ball milling and subsequent annealing, is a much simpler method for the production of carbon nanotubes ${ }^{36-39}$ and could be the key to cheap methods of production industrially. It is well established that mechanical attrition of this type can lead to fully nanoporous microstructures, although it was not until recently that nanotubes of carbon and boron nitride have been produced from these powders by thermal annealing. Essentially, the method consists of loading graphite powder ( $99.8 \%$ purity) into a stainless steel container along with 4 hardened steel balls. The container is purged and argon gas $(300 \mathrm{kPa})$ is introduced and the milling is carried out at room temperature for several hours (up to 150 hours). Following milling, the powder is annealed under a nitrogen (or argon gas flow) at temperatures of $1400^{\circ} \mathrm{C}$ for 6 hours. We believe however, that lower temperatures are possible. The mechanism of this process is not known but it is thought that the ball milling process forms nanotube nuclei and the annealing process activates the nanotube growth. Preparation of carbon nanotubes by ball milling was first published by the Australian group led by Chen ${ }^{36,37}$ and by Huang et $\mathrm{al}^{38}$ in 1999. Chen and co-workers ${ }^{36,37}$ have shown by X-ray diffraction (XRD) patterns that the milling of the graphite powder is contaminated by iron from the steel balls. The level of contamination increases with milling time. It is this fortuitous contamination by iron that would seem to act as the catalyst for the formation of the nanotubes. Work from this group has shown that multiwalled nanocarbons are formed but single walled nanotubes are more difficult to prepare.

\section{SIGNIFICANCE}

These are:

1. As new electronic industry components. The electronics industry has begun looking for alternative materials because continuing miniaturization of silicon components and fine control of electronic properties at smaller scales poses intractable problems. The smallest transistors known to humankind are carbon nanotubes ${ }^{40}$ and fullerenes. For delicate electronics experiments, singlewalled tubes of specific stereochemistry (geometry) and length must be synthesised. Some success has now been achieved in controlling length and junctions ${ }^{41}$ and have been made between electronic components so that nanoelectronics are a reality. Nevertheless bulk production of transistor nanotubes has not been achieved. A recent paper demonstrates they can be used as active channels of field effect transisters. ${ }^{42}$

2. As display screens. Nanotubes emit electrons under the influence of an electrical field ${ }^{43,44}$. This is called field emission. Field emission has application in flat-panel displays for example, as television screens. A television or computer monitor relies on a gun to shoot electrons at the pixels of a phosphor screen, which light up as ordered. Millions of nanotubes arranged just below the screen could take the place of the gun. Nanotube flat screens should have life like resolution, and possible three dimensional television applications. $\operatorname{Ren}^{45}$ has produced neat forests of multiwalled nanotubes directly on glass surfaces, showing the potential of growing nanotubes in place ${ }^{45-48}$ with the surface as substrate. Individual carbon nanotubes have also been synthesised on patterned silicon wafers ${ }^{48}$ so that field emission is an on going area of urgent research ${ }^{49-51}$. Researchers at Samsung have a 
prototype that requires half the power of conventional liquid-crystal displays, and the nanotubes appear to meet the 10,000-hour lifetime typically demanded for commercial applications. The issue to be resolved is the orderly operation of the nanotubes which requires synthesis of single walled nanotubes of specific stereochemistry.

3. Nanotubes may have a role in hydrogen storage ${ }^{52}$. Whilst its energy content on a mass-for-mass basis is better than petrol, hydrogen has difficulty competing with fossil fuel because it is a gas. A hydrogen gas fuel tank that contained a store of energy equivalent to a petrol tank would be more than 3,000 times bigger than its conventional cousin. Nanotubes could be used for this task because they absorb one hydrogen atom for every two carbon atoms. What is more, almost $80 \%$ of the stored hydrogen could be released from the tubes at room temperature and pressure, with the rest released after the tube was heated. The target for hydrogen capacity that would interest electric-car manufacturers is about 6.5 percent by weight in whatever storage medium is used. Nanotubes may also store helium ${ }^{53}$. Hydrogen or helium uptake would be better controlled with single walled nanotubes of specific geometry.

4. Carbon nanotubes may also have a use in batteries. Graphite can store lithium ions, the charge carriers for some batteries. Six carbon atoms are present for every lithium ion. The geometry inherent in bundles of nanotubes may allow them to accommodate more than one lithium per six carbons particularly if the material consists of one particular nanotube type and hence produce a better battery.

5. The high Youngs Modulus ${ }^{54-57}$ may mean that nanotubes are useful as materials. Nanotubes are about six times lighter and 10 times stronger than steel but they will need to be bound together in a macroscopic fibres to be employed for large scale uses. Carbon fiber is already a proven winner in composite materials, and carbon nanotubes certainly have promise in the same market because of their exceptionally high length-to-diameter ratio, the vital figure in stress transmission. Nanotube fibres with mixed geometries have now been produced, and although they are weak in strength ${ }^{58}$ they have flexible properties unlike traditional graphitic fibres. Moreover, the electrical properties in colloidal solution allow nanotubes to be collected in a molecularly continuous fibre prepared at room temperature with few defects. Conventional carbon fibres need to be prepared at high temperatures in which graphitic planes are aligned and which defects are common. The strength and properties of single geometry nanotube fibres may be outstanding.

6. As actuators. Recently a team including Professor Wallace at Wollongong reported ${ }^{59}$ that SWNTs can deform reversibly when electrochemically charged. These actuators were formed with sheaths of bundled SWNT ropes. Thus the electrical properties can be used to generate mechanical motion from electrical motion. This has been achieved on the macroscale but could be achieved at nano level to produce nano electric actuators like flagella. Single geometry nanotubes would produce more effective machines.

7. Other Nanomachines. Nanomachines exist in nature because nature employs self-assembly processes at the molecular scale in order to produce an extraordinary diverse array of life forms. If chemists and engineers could operate at nature's nanometre level, then they could design and produce unique machines. While it is the authors belief that the major breakthroughs in nanomachines will come from modification of nature's own machines, the concept of engineering molecular machines of which there is no natural equivalent (for example, heat pumps, actuators as described above, rotating electric motors, even petroleum refineries) is fascinating. Substituted nanotubes are the nanogears of Drexlers ${ }^{60,61}$ fanciful and inspirational mechanical nanomachines. While this was science fiction, it recently became science reality. Recently researchers from the University of 
California, Berkeley have developed what can be called the first nano-bearings by attaching one end of a multiwalled carbon nanotube to a stationary gold electrode. They then used a nanomanipulator to pull the inner tubes out. Using a scanning electron microscope, the team could watch how the inner core was pulled back inside by intermolecular Van der Waals forces thus making the MWNTs act like a bearing ${ }^{62}$. Another extremely interesting application of the bearing is a so-called nanoswitch. By applying a voltage to the bearing, researchers can very rapidly force the central tube to stick out.

\section{EXPERIMENTAL}

\section{Plasma arcing}

Details of the arcing process have been reported elsewhere ${ }^{3,8,10,14,17}$. A $6.33 \times 150 \mathrm{~mm}$ graphite rod was prepared for arcing by drilling a $3.77 \times 100 \mathrm{~mm}$ hole down its axis. The hole was then filled with a mixed powder of graphite and naphthalene before plugging the rod with a $15 \times 3.17 \mathrm{~mm}$ graphite cap. The percentages of naphthalene in the fill of the rods were 0 (control), 1, 2, 5, 10, 30, $50,60,70,90,99$ and $100 \% \mathrm{w} / \mathrm{w}$. The rod with arcing mixture was mounted inside and at one end of a cylindrical chamber and at the other end a $13 \times 30 \mathrm{~mm}$ graphite rod was also mounted and acted as the cathode.

Once sealed, the chamber was evacuated by a rotary pump to $13.3 \mathrm{~Pa}$, filled with high purity helium to atmospheric pressure, re-evacuated to $13.3 \mathrm{~Pa}$ and then filled again with helium, but only up to $33.3 \mathrm{kPa}$. This evacuation and filling procedure was performed to create an atmosphere inside the chamber, which is optimal for the nucleation of fullerenes. After turning on the direct current arc welder power source, the anode was manually advanced towards the cathode at a rate of $10 \mathrm{~mm} / \mathrm{min}$. When the electrodes were $1 \mathrm{~mm}$ apart, a plasma arc formed which caused the anode to evaporate. Fullerene-containing soot coated the inside of the chamber and a carbonaceous deposit formed on the cathode. The cathode deposits were simply broken off the cathode surface and cleaved along the longitudinal axis with a screwdriver blade yielding two halves. One half was studied by electron microscopy. The remaining half was scraped from the deposit and examined by the other techniques described below.

\section{Ball Milling}

Cobalt powder (100 mesh, $99.9 \%$ purity) was ball milled at room temperature in stainless steel mill with ten hardened steel balls. Either $0.1 \mathrm{~g}$ or $1.0 \mathrm{~g}$ of cobalt was pre-milled before graphite addition, in order to investigate the effects of $1 \%$ and $10 \%$ cobalt powder as a catalytic agent. Nitrogen gas was used to purge the mill and the milling atmosphere was carried under $200 \mathrm{kPa}$ of nitrogen gas. After pre-milling of cobalt, $10 \mathrm{~g}$ of graphite was loaded into the mill and purged with nitrogen gas and ball milled under $200 \mathrm{kPa}$ of nitrogen gas. Ball milling was carried out for $6,12,18$, $24,30,36,42,48$ and 54 hours. After each ball milling experiment, the milled powder was thermally annealed in a tube furnace for 6 hours at $1200^{\circ} \mathrm{C}$ in a flow of ultra high purity argon gas. The powder was loaded into the tube furnace and was then purged with argon gas for 0.5 hours before temperature ramping. Laser Raman spectroscopy, powder X-ray diffraction spectroscopy and transmission electron microscopy are used to elucidate the crystalline structure and phase transformations of graphite powders under different milling times and annealing. 


\section{Transmission electron microscopy}

A Philips EM430 Transmission Electron Microscope (TEM) operating at $300 \mathrm{kV}$ and a Philips EM400 TEM operating at $100 \mathrm{kV}$ were used to image the internal structures of the samples. Samples were prepared for viewing in TEM by suspending a small portion (1-5 $\mathrm{mg}$ ) of cathode deposit or fullerene black in approximately $15 \mathrm{~mL}$ of absolute ethanol. To ensure proper separation of the particles, they were dispersed in the solution ultrasonically. Finally, a few drops of the solution were applied onto a copper grid coated with a holey carbon film.

Photographic prints were obtained of the TEM displays. A $5 \times 5 \mathrm{~mm}$ grid transparency was overlayed on each print to record the grid reference of each particle observed. Co-ordinates A1 were placed at the top left-hand corner of the prints. For nanotubes, inner (i) and outer diameters (o) were measured from the photographic plate and then calculated from the magnification factors. The nanotube wall thickness $(\mathrm{n})$ was calculated as $(\mathrm{i}+\mathrm{o}) / 2$. Sufficient resolution was not obtained to independently count the number of of graphitic layers that make up the wall of the nanotube. Instead, using a value of $0.34 \mathrm{~nm}$ to represent the known average spacing between graphitic planes, the number of concentric tubes was calculated as $n / 0.34$.

\section{Raman Spectroscopy}

Raman spectra were acquired on a Renishaw Raman Microprobe Laser Raman Spectrometer using a charge coupled detector. The collection optics are based on a Leica DMLM microscope. A refractive glass $50 \mathrm{X}$ objective lens was used to focus the laser onto a $2 \mu \mathrm{m}$ spot to collect the backscattered radiation. The $514.5 \mathrm{~nm}$ line of a $5 \mathrm{~W} \mathrm{Ar}{ }^{+}$laser (Coherent Innova Model 70, continuous wave) was used to excite the sample. Surface laser powers of $1.0-1.5 \mathrm{~mW}$ were used because the milled and annealed graphite samples were found to burn under higher energies. An accumulation time of $30 \mathrm{~s}$ and 10 scans were used and gave adequate signal-to-noise ratios of the spectra. The scan ranges were $1000-1700 \mathrm{~cm}^{-1}$ and $2150-3400 \mathrm{~cm}^{-1}$. Milled and annealed graphite samples were deposited on clean aluminum microscope slides and irradiated with the laser to obtain spectra. The operating conditions of the Raman spectrometer were optimised by focussing the laser ( $20 \mathrm{~mW}$ power) onto a film of silicon and adjusting the alignment of the laser to obtain the greatest possible signal at approximately $520 \mathrm{~cm}^{-1}$ with an accumulation time of $1 \mathrm{~s}$. The spectrometer is controlled and the spectral processing is done using GRAMS/32 software. The full width half maximum used in the graphite phase assessments are determined by drawing a line parallel that intersects the middle of a vertical line connecting the maximum (or minimum) of the band and the local baseline. The distance between both intersection points of this parallel and the spectrum is the half-line-width.

\section{Powder X-ray diffraction spectroscopy}

The crystalline structure of the ball milled and annealed samples were investigated by powder Xray diffraction spectroscopy. A Siemens Kristalloflex X-ray generator equipped with two powder cameras with Bragg-Brentano geometry was used. A Philips PW2276/20 X-ray tube was used at a power of $40 \mathrm{~mA}$ and $40 \mathrm{kV}$ to produce cobalt X-rays. Samples were mounted in an aluminium sample holder. The holder and sample were placed on the diffractometer and an XRD pattern 
collected from 0.10 to $110.00^{\circ} 2 \theta$, at intervals of $0.02^{\circ} 2 \theta$. Count times of 2 seconds per interval were employed.

\section{RESULTS AND DISCUSSION}

\section{Plasma Arcing}

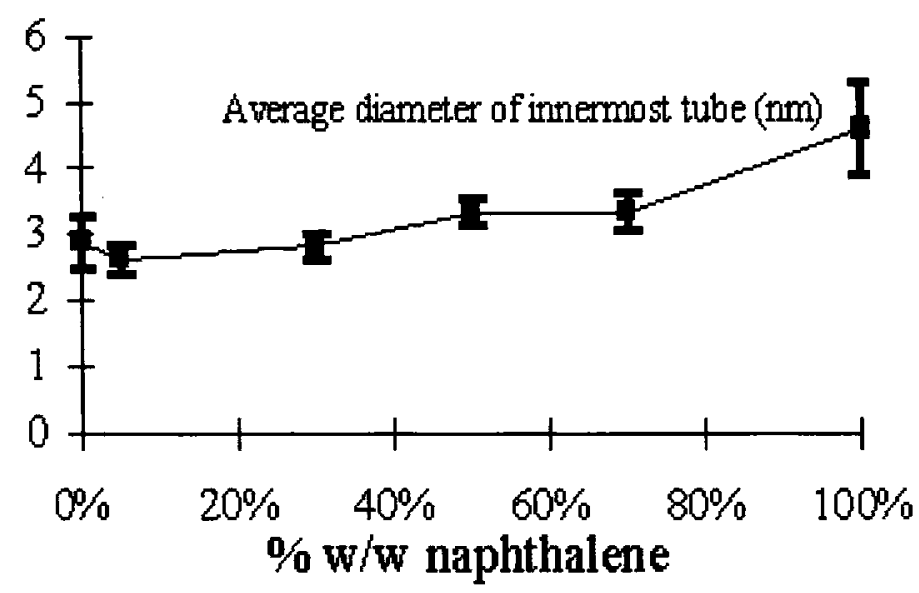

Fig. 4: Effect of naphthalene on void spacing on zig-zag nanotubes by arcing during plasma arcing.

Figure 4 shows the results of the naphthalene in the anode in arcing experiments. During anode plasma arcing of graphite, like fullerenes, nanotubes form only from $\mathrm{C} 1$ units brought to the cathode surface. However we now believe this is not true when other materials are used as an anode. As noted, carbon experiences a temperature from around $2000 \mathrm{~K}$ at the centre of the arc to around it certainly means that fullerene synthesis occurs at lower temperatures at the edge of the arc. Likewise, in nanotube formation it must be possible for molecules surviving at the edge of the arc to tumble back into the electrode surface and become incorporated. In experiments in which naphthalene has been added to the anode the average void space of the nanotubes in the cathode deposit increases by up to two nanometers compared with graphite experiments. Presumably the larger void space occurs because there are more six membered ring structures available when naphthalene is present in the arc and hence the half fullerene or related caps are wider. The wider tubes are more predominant at the outer diameter regions of the anode deposit possibly because naphthalene more readily survives here and can be incorporated. We have evidence that the nanotubes formed in the presence of naphthalene during arcing experiments are predominantly zig-zag, probably because in this structure the naphthalene is incorporated at $180^{\circ}$ to the cap. The results give us hope for similar success in ball milling experiments. The point is, with ball milling there should be less contribution of nanotubes formed through $\mathrm{C} 1$ processes in which stereochemistry is less controlled

Others have found that inclusion of certain inorganic chemicals in the anode, for example, cobalt, produces single walled nanotubes ${ }^{18-22}$ a result confirmed by us ${ }^{63}$. Naphthalene also affects the product distribution in experiments with cobalt additives. 


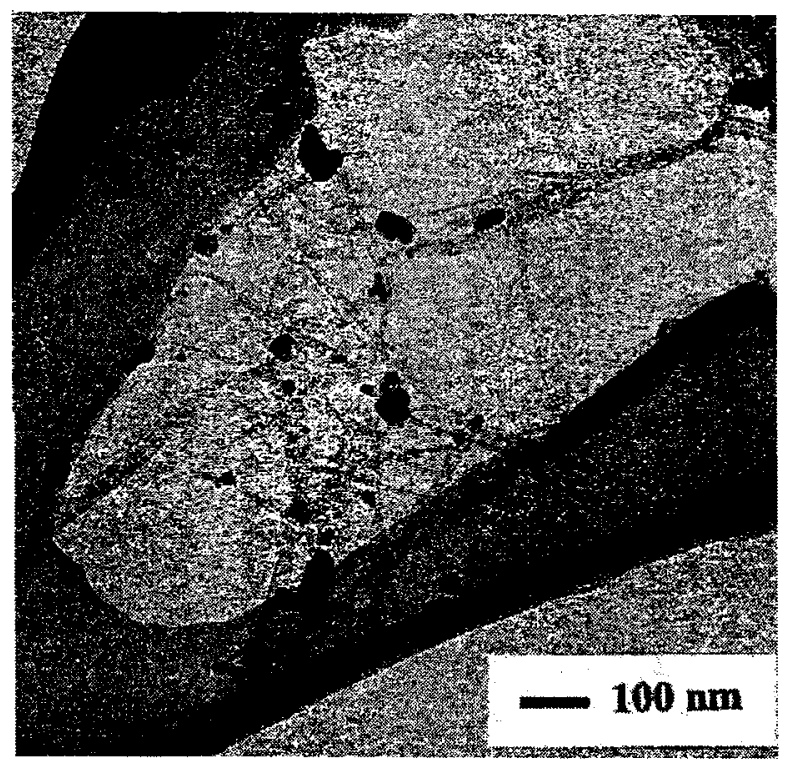

Fig. 5: TEM image of carbon nanotubes taken from a graphite sample after annealing at $1400^{\circ} \mathrm{C}$ for $6 \mathrm{hr}$ in $\mathrm{N}_{2}$ gas. The sample has been previously ball milled for $150 \mathrm{hr}$ (Chen et $\mathrm{al}^{36}$ ). Ball Milling

Chen et al $^{36,37}$ studies showed that iron may act as a catalyst. In our own plasma arcing studies we have demonstrated that cobalt has assisted the formation of single walled nanotubes. Therefore we have chosen to use cobalt as a catalytic agent in our preliminary investigations of ball milling and subsequent annealing of graphite. Fig. 5 shows TEM micrographs taken from a graphite sample after annealing at $1400^{\circ} \mathrm{C}$ for 6 hours in nitrogen gas. The sample had been previously ball milled for 150 hours. Later studies will concentrate on using coal, once the method has been established for graphite and cobalt additive.

Table 1: X-ray diffraction data of milled and annealed graphite and $10 \%$ cobalt powders.

\begin{tabular}{|c|c|c|c|c|c|c|}
\hline $\begin{array}{c}\text { Sample } \\
(\mathrm{hr})\end{array}$ & $\begin{array}{c}\% \\
\mathrm{Co}\end{array}$ & $\begin{array}{c}\mathrm{d}_{002} \\
\text { FWHM } \\
\left({ }^{\circ}\right) \\
\text { mill }\end{array}$ & $\begin{array}{c}\mathrm{d}_{002} \\
\text { FWHM } \\
\left({ }^{\circ}\right) \\
\text { ann }\end{array}$ & $\begin{array}{c}\% \\
\text { Co }\end{array}$ & $\begin{array}{c}\mathrm{d}_{002} \\
\text { FWHM } \\
\left({ }^{\circ}\right) \\
\text { mill }\end{array}$ & $\begin{array}{c}\mathrm{d}_{002} \\
\text { FWHM } \\
\left({ }^{\circ}\right) \\
\text { ann }\end{array}$ \\
\hline 6 & 1 & 0.35 & 0.40 & 10 & 0.30 & 0.40 \\
\hline 12 & 1 & 0.80 & 0.80 & 10 & 0.55 & 0.50 \\
\hline 18 & 1 & 0.60 & 0.70 & 10 & 0.60 & 0.50 \\
\hline 24 & 1 & 0.80 & 0.60 & 10 & 0.80 & 0.50 \\
\hline 30 & 1 & 1.00 & 0.06 & 10 & 0.70 & 0.50 \\
\hline 36 & 1 & 1.20 & 0.60 & 10 & 0.70 & 0.50 \\
\hline 42 & 1 & 1.30 & 0.50 & 10 & 0.70 & 0.50 \\
\hline 48 & 1 & 1.50 & 0.50 & 10 & 0.70 & 0.50 \\
\hline 54 & 1 & 1.50 & 0.40 & 10 & 0.70 & 0.50 \\
\hline
\end{tabular}

$d_{002^{-}}$predominant crystal plane in graphite, FWHM-Peak measured at Full width half maximum and mill- milled, annannealed powder. 
Shown in Table 1 are the powder X-ray diffraction parameters derived from each milling and annealing interval to elucidate the phase transformations of graphite, for 1 and $10 \%$ cobalt added. Broadening occurs as expected with milling at both cobalt concentrations. However at the higher concentration of cobalt $(10 \%)$ the reaction is over at $30 \mathrm{hr}$ while it continues to $48 \mathrm{hr}$ at the lower concentration (1\%). This suggests a catalytic effect. It is interesting to note that in milling, the higher cobalt concentration has lower line width half maximum height indicating more ordering. Little information is available by X-ray diffraction.

Table 2: Raman spectroscopic parameters of milled and annealed graphite and $1 \%$ cobalt powders.

\begin{tabular}{|c|c|c|c|c|c|c|c|c|}
\hline $\begin{array}{c}\text { Sample } \\
\text { (hr) }\end{array}$ & $\begin{array}{c}\mathrm{D} \\
\text { FWHM } \\
\left(\mathrm{cm}^{-1}\right) \\
\text { mill } \\
\end{array}$ & $\begin{array}{c}\text { D } \\
\text { FWHM } \\
\left(\mathrm{cm}^{-1}\right) \\
\text { ann } \\
\end{array}$ & $\begin{array}{c}\mathrm{G} \\
\text { FWHM } \\
\left(\mathrm{cm}^{-1}\right) \\
\text { mill }\end{array}$ & $\begin{array}{c}\text { G } \\
\text { FWHM } \\
\left(\mathrm{cm}^{-1}\right) \\
\text { ann }\end{array}$ & $\begin{array}{c}\text { D/G } \\
\text { FWHM } \\
\left(\mathrm{cm}^{-1}\right) \\
\text { mill }\end{array}$ & $\begin{array}{c}\mathrm{D} / \mathrm{G} \\
\mathrm{FWHM} \\
\left(\mathrm{cm}^{-1}\right) \\
\text { ann }\end{array}$ & $\mathrm{I}_{\mathrm{D}} /\left(\mathrm{I}_{\mathrm{D}}+\mathrm{I}_{\mathrm{G}}\right)$ & $\mathrm{I}_{\mathrm{D}} /\left(\mathrm{I}_{\mathrm{D}}+\mathrm{I}_{\mathrm{G}}\right)$ \\
\hline 6 & 50 & 50 & 25 & 25 & 2.0 & 2.0 & $23.2 \pm 0.2$ & $23.5 \pm 0.5$ \\
\hline 12 & 50 & 50 & 30 & 30 & 1.7 & 1.7 & $36.4 \pm 0.2$ & $32.9 \pm 0.4$ \\
\hline 18 & 55 & 50 & 35 & 25 & 1.6 & 2.0 & $39.5 \pm 0.6$ & $34.3 \pm 0.3$ \\
\hline 24 & $\overline{55}$ & 55 & 40 & 30 & 1.4 & 1.8 & $42.5 \pm 0.8$ & $38.2 \pm 0.1$ \\
\hline 30 & 60 & 55 & 50 & 35 & 1.2 & 1.6 & $46.8 \pm 0.2$ & $40.8 \pm 0.4$ \\
\hline 36 & 60 & 55 & 55 & 45 & 1.1 & 1.2 & $48.4 \pm 0.1$ & $42.1 \pm 1.1$ \\
\hline 42 & 60 & 55 & 60 & 40 & 1.0 & 1.4 & $49.5 \pm 0.2$ & $42.3 \pm 0.5$ \\
\hline 48 & 60 & 55 & 60 & 40 & 1.0 & 1.4 & $49.6 \pm 0.1$ & $41.5 \pm 0.4$ \\
\hline 54 & 60 & 50 & 60 & 40 & 1.0 & 1.4 & $50.0 \pm 0.1$ & $42.7 \pm 0.1$ \\
\hline
\end{tabular}

$D$ - $D$ band (Disordered carbon), G- $G$ band (Graphitic carbon), FWHM-Bands measured at Full width at half maximum, mill - milled, ann-annealed powder and $I_{D} /\left(I_{D}+I_{G}\right)$-Degree of disorder measured by band area.

Shown in Table 2 are the laser Raman spectroscopic parameters derived from each milling and annealing interval to elucidate the phase transformations of graphite, for $1 \%$ cobalt added. It can be seen from the disordered to graphite carbon band that $I_{D} /\left(I_{D}+I_{G}\right)$ increases with time of annealing and with time of milling. Thus Raman spectroscopy shows that reactions are occurring in both annealing and milling. The ratio of disordered carbon linewidth at half height to graphitic carbon (D/G FWHM) also changes with milling and annealing time. This may be a useful parameter in preparing annealed or milled mixtures.

Table 3: Raman spectroscopic parameters of milled and annealed graphite and $10 \%$ cobalt powders.

\begin{tabular}{|c|c|c|c|c|c|c|c|c|}
\hline $\begin{array}{c}\text { Sample } \\
(\mathrm{hr})\end{array}$ & $\begin{array}{c}\text { D } \\
\text { FWHM } \\
\left(\mathrm{cm}^{-1}\right) \\
\text { mill }\end{array}$ & $\begin{array}{c}\text { D } \\
\text { FWHM } \\
\left(\mathrm{cm}^{-1}\right) \\
\text { ann }\end{array}$ & $\begin{array}{c}\mathrm{G} \\
\text { FWHM } \\
\left(\mathrm{cm}^{-1}\right) \\
\text { mill }\end{array}$ & $\begin{array}{c}\text { G } \\
\text { FWHM } \\
\left(\mathrm{cm}^{-1}\right) \\
\text { ann }\end{array}$ & $\begin{array}{c}\text { D/G } \\
\text { FWHM } \\
\left(\mathrm{cm}^{-1}\right) \\
\text { mill }\end{array}$ & $\begin{array}{c}\text { D/G } \\
\text { FWHM } \\
\left(\mathrm{cm}^{-1}\right) \\
\text { ann }\end{array}$ & $\mathrm{I}_{\mathrm{D}} /\left(\mathrm{I}_{\mathrm{D}}+\mathrm{I}_{\mathrm{G}}\right)$ & $\mathrm{I}_{\mathrm{D}} /\left(\mathrm{I}_{\mathrm{D}}+\mathrm{I}_{\mathrm{G}}\right)$ \\
\hline 6 & 50 & 50 & 25 & 25 & 2.0 & 2.0 & $27.0 \pm 0.1$ & $23.9 \pm 0.8$ \\
\hline 12 & 50 & 50 & 30 & 25 & 1.7 & 2.0 & $35.6 \pm 0.8$ & $29.6 \pm 0.4$ \\
\hline 18 & 50 & 50 & 25 & 25 & 2.0 & 2.0 & $36.9 \pm 0.4$ & $34.6 \pm 0.2$ \\
\hline 24 & 55 & 45 & 30 & 25 & 1.8 & 1.8 & $37.1 \pm 0.2$ & $38.2 \pm 0.1$ \\
\hline 30 & 55 & 50 & 35 & 25 & 1.6 & 2.0 & $38.1 \pm 0.3$ & $32.3 \pm 0.3$ \\
\hline 36 & 55 & 50 & 40 & 25 & 1.4 & 2.0 & $38.4 \pm 0.4$ & $32.5 \pm 0.1$ \\
\hline 42 & 55 & 50 & 50 & 25 & 1.1 & 2.0 & $41.0 \pm 0.2$ & $33.8 \pm 0.2$ \\
\hline 48 & 55 & 50 & 40 & 25 & 1.4 & 2.0 & $42.7 \pm 0.1$ & $33.6 \pm 0.2$ \\
\hline 54 & 50 & 50 & 40 & 25 & 1.3 & 2.0 & $42.9 \pm 0.2$ & $32.6 \pm 0.4$ \\
\hline
\end{tabular}

$D$ - D band (Disordered carbon), G- G band (Graphitic carbon), FWHM-Bands measured at Full width at half maximum, mill - milled, ann-annealed powder and $I_{D} /\left(I_{D}+I_{G}\right)$-Degree of disorder measured by band area. 
Shown in Table 3 are the results for $10 \%$ cobalt. Now like at the lower concentration, $I_{D} /\left(I_{D}+I_{G}\right)$ increases for both milling and annealing but the values are much lower suggesting greater ordering. D/G FWHM drops for milling but not for annealing. This is significant since at this concentration nanotubes are formed by plasma arcing but not at $1 \%$ cobalt concentration (Table 2). Thus the results demonstrate the importance of cobalt ordering both in milling and annealing.

\section{CONCLUSIONS}

Carbon nanotube stereochemistry can be altered by additives. This has been demonstrated by plasma arcing. Carbon nanotubes can also be made by ball milling. The value of cobalt on affecting the crystallinity of graphitic particles in milling and subsequent annealing has been demonstrated.

\section{REFERENCES}

1. Iijima, S., "Helical microtubules of graphitic carbon". Nature, 354, (1991), pp56-58.

2. Greenwood, P., Nakat, H., Willett, G., Wilson, M., Strachan, M., and Attalla, M., "Laser ablation Fourier-transform mass-spectrometric investigation of coals and related model substances". Prep. Div. Fuel. Amer. Chem. Soc. 34(3) (1989), pp773-779.

3. Pang, L.,Vassallo, A., Wilson, M., "Fullerenes from coal". Nature 352, (1991), pp480-481.

4.Tohji, K., Saito, K., Matsuoka, I., Sogabe, T., Nagasawa, K., Fullerenes V94-24, Proc Rec Adv Chem and Phys Fullerenes and Rel Mat, Kadish, K and Ruoff, R (Eds), Electrochem Soc, NJ, pp132-137, (1994).

5.Tohji, K., Takanashi, H., Shinoda, Y., Shimizu, S., Jeyadevan, B., Mastsuaka, I., Saito, Y., Kasuya, A., Ito, S. and Nishina, Y. "Purification procedure for single-walled nanotubes". J. Phys. Chem. B, 101, (1997) pp1974-1978.

6.Weston, A., Murthy, M. and Lalvani, S. "Synthesis of fullerenes from coal". Fuel Processing Technology, 45, (1995) pp203-212.

7.Weston, A. and Murthy, M. "Synthesis of fullerenes: an effort to optimize process parameters". Carbon, 34, (1996), pp1267-1274.

8.Pang, L., Vassallo, A., Wilson, M. "Fullerenes from coal: A self consistent preparation and purification process". Energy and Fuels, 6, (1992), pp176-179.

9.Pang, L., Prochazka, L., Quezada, R., Wilson, M., Pallasser, R, Fisher, K, Fitzgerald, J., Taylor, G., Willett, G. and Dance, I. "Competitive reactions during plasma arcing of carbonaceous materials". Energy and Fuels, 9, (1995), pp3844.

10.Geldard, L., Keegan, J., Young, B. and Wilson, M. "Pathways of polycyclic hydrocarbon formation during plasma arcing of carbonaceous materials". Fuel, 77, (1997), pp15-18.

11.Crowley, C., Taylor, R., Kroto, H. W., Walton, D. R. M., Cheng, P-C., Scott, L. T. "Pyrolytic production of fullerenes". Synthetic Metals, 77, (1996), pp17-22.

12.Dance, I., Fisher, K., Willet, G. and Wilson, M. "Buckminsterfullerene and liquid-crystal mesophase". J Phys Chem, 95, (1991), pp8425-8428.

13.Rose, H., Dance, I, Fisher, K., Smith, D., Willett, G., Wilson, M. "Endohedral barium and strontium fullerenes". $J$ Chem. Soc. Chem. Comm., (1993), pp1361-1363.

14. Pang, L., Wilson, M., Pallasser, R. and Prochazka, L. "Isotope effects in plasma arcing experiments with various carbon anodes". Energy and Fuels, 9, (1995), pp704-706.

15. Fisher, K., Largeau, C. and Derenne, S. "Can oil shales be used to produce fullerenes?". Org Geochem, 24, (1996), pp715-723.

16. Thess, A., Lee, R., Nikolaev, P., Dai, H., Petit, P., Robert, J., Xu, C., Lee, Y., Gon Kim, S., Rinzler, A.G., Colbert, D.T., Scuseria G., Tománek, D., Fischer, J.E. and Smalley, R.E. "Crystalline ropes of metallic carbon nanotubes". Science, 273, (1996), pp483-485.

17. Wilson, M.A., Patney, H., Kalman, J. "New developments in the formation of nanotubes from coal". Fuel (2001) (in press).

18. Gennett, T., Dillon, A.C., Allerman, J.L., Jones, K.M., Hasoon, F.S. and Heben, M.J. "Formation of single wall carbon nanotube superbundles". Chem. Mater., 12, (2000), pp599-601. 
19. Puretzky, A.A., Geohegan, D.B., Fan, X. and Pennycook, S.J. "Dyanamics of single wall carbon nanotube synthesis by laser vaporization". Appl. Phys A., 70, (2000), pp153-160.

20. Gamaly, E.G., Rode, A.V., Maser, W.K., Munoz, E., Benito, A.M., Martinez, M.T. and de la Fluente, G.F. "Single walled carbon nanotubes formation with a continous $\mathrm{CO}_{2}$ laser: experiments and theory". Appl. Phys A, 70, (2000), pp161-168.

21. Guo, T., Nikolaev, P., Thess, A., Colbert, D.T., and Smalley, R.E. "Catalytic growth of single-walled nanotubes by laser vaporization". Chem. Phys. Lett., 243, (1995), pp49-54.

22. Journet, C., Maser, W.K., Bernie, P., Loiseau, A., Lamy de la Chapelle, M., Lefrant, S., Deniard, P., Lee R., and Fischer, J.E. "Large-scale production of single-walled carbon nanotubes by the electric-arc technique". Nature, 388, (1997), pp756-758.

23. Ren, Z.F., Huang, Z.P., Xu, J.W., Wang, J.H., Bush, P., Siegal, M.P., and Provencio, P.N. "Synthesis of large arrays of well-aligned carbon nanotubes on glass". Science, 282, (1998), pp1105-1107.

24. Liu, J., Casavant, M.J., Cox, M., Walters, D.A., Boul, P., Lu,W., Rimberg, A.J., Smith, K.A., Colbert, D.T. and Smalley, R.E. "Controlled deposition of individual single walled carbon nanotubes on chemically functionalised templates". Chem. Phys Letters, 303, (1999), pp125-129.

25. Liu, Z., Shen, Z., Zhu, T., Hou, S, Ying, L., Shi, Z. and Gu, Z. "Organizing single-walled carbon nanotubes on gold using a wet chemical self-assembling technique". Langmuir, 16, (2000), pp3569-3573.

26. Grobert, N., Terrones, M., Trasobares, S., Kordatos, K., Terrones, H., Olivares, J., Zhang, J.P, Redlich, Ph., Hsu W.K., Reeves, C.L., Wallis, D.J., Zhu, Y.Q., Hare, J.P., Pidduck, A.J., Kroto, H.W. and Walton, D.R.M. "A novel route to aligned nanotubes and nanofibers using laser-patterned catalytic substrates". Appl. Phys. A, 70, (2000), pp175-183.

27. Yang, Y., Huang, S., He, H., Mau, A.W.H. and Dai, L.M. "Patterned growth of well-aligned carbon nanotubes: A photolithographic approach". J. Amer. Chem. Soc., 121, (1999), pp10832-10833.

28. Huang, S., Dai, L.M. and Mau, A.W.H. "Nanotube crop circles". J. Mater. Chem., 9, (1999), pp1221-1222.

29. Huang, S., Dai, L.M. and Mau, A.W.H. "Patterned growth and contact transfer of well-aligned carbon nanotube films". J. Phys. Chem. B.,103, (1999), pp4223-4227.

30. Huang, S., Mau, A.W.H. Turney, T.W., White, P.A. and Dai, L.M. "Patterned growth of well aligned carbon nanotubes: A soft-lithographic approach". J. Phys. Chem. B, 104, (2000), pp2193-2196.

31. Li De-C., Dai, L.., Huang, S., Mau, A.W.H. and Wang, Z.L. "Structure and growth of aligned carbon nanotube films by pyrolysis". Chem. Phys. Letters, 316, (2000), pp349-355.

32. Terrones, M., Grobert, N., Zhang, J.P., Terrones, H., Olivares, J., Hsu, W.K., Hare, J.P., Cheetham, A.K., Kroto, H.W., and Walton, D.R.M. "Preparation of aligned carbon nanotubes catalysed by laser-etched cobalt films". Chem. Phys. Letters., 285, (1998), pp299-305.

33. Cassell, A.M., Raymakers, J.A., Kong, J., and Dai, H. 'Large Scale CVD Synthesis of Single-Walled Carbon Nanotubes". J. Phys. Chem. B, 103, (1999), pp6484-6492.

34. Kokai, F., Takahashi, K., Kasuya, D. Ichihashi, L., Yudasaka, M. Lijima, S. "Synthesis of single-wall carbon nanotubes by millisecond pulsed $\mathrm{CO}_{2}$ laser vaporization at room temperature". Chem. Phys. Letters, 332, (2000), pp449454.

35. Sinha, A.K., Hwang, D.W., Hwang, L.-P. "A novel approach to bulk synthesis of carbon nanotubes filled with metal by a catalytic chemical vapour deposition method". Chem. Phys. Letters, 332, (2000), pp455-460.

36. Chen, Y., Fitz Gerald, J., Chadderton, L.T., and Chaffron, L."Investigation of nanoporous carbon powders produced by high energy ball milling and formation of carbon nanotubes during subsequent annealing". J. Metastable and Nanocrystalline Mater., 2-6, (1999), pp375-380.

37. Chen, Y., Fitz Gerald, J., Chadderton, L.T., and Chaffron, L. "Nanoporous carbon produced by ball milling". Appl. Phys. Lett., 74, (1999), pp2782-2784.

38. Huang, J.Y., Yasuda, H., and Mori, H. "Highly curved carbon nanostructures produced by ball milling". Chem. Phys. Letters., 303, (1999), pp130-134.

39. Börner, I., and Eckert, J. "Nanostructure formation and steady-state grain size of ball-milled iron powders". Mater. Sci. Engineer., A226-228, (1997), pp541-545.

40. Tombler, T.W., Zhou, C. K.J. and Hongjie, D. "Gating individual nanotubes and crosses with scanning probes". Appl. Phys. Letters, 76, (2000), pp2412-2414.

41. Fuhrer, M.S. Nygard, J., Shih, L., Forero, M., Yoon, Y-G., Mazzoni, M.S.C., Choi, H.J., Ihm, J., Louie, S.G., Zettl, A. and NcEuen, P.L. "Crossed nanotube junctions". Science, 288, (2000), pp494-497.

42. Derycke, V., Martel, R., Appenzeller, J and Avouris, P. "Carbon Namotube Inter- and Intramolecular Logic Gates", Nanoletters, (2001) (in press). 
43. Tans, S.J., Verschueren, R.M., and Dekker, C. "Room-temperature transistor based on a single carbon nanotube". Nature, 393, (1998), pp49-52.

44. Martel, R., Schmidt, T., Shea, H.R., Hertel, T. and Avouris, P. "Single- and multi-wall carbon nanotube field-effect transistors". Appl. Phys. letters, 73, (1998), pp2447-2449.

45. Ren, Z.F., Huang, Z.P., Xu, J.W., Wang, J.H., Bush, P., Siegal, M.P., and Provencio, P.N. "Synthesis of large arrays of well-aligned carbon nanotubes on glass". Science, 282, (1998), pp1105-1107.

46. Powell, P.N., "Flat panel displays - large area colour nanotube FED debuts". Laser Focus World, 36, (2000), $24-29$.

47. Chung, D.S., Choi, W.B., Kang, J.H., Kim, H.Y., Han, I.T., Park, Y.S., Lee, Y.H., Lee, N.S., Jung, J.E., and Kim, J.M. "Field emission from 4.5 in. single-walled and multiwalled carbon nanotube films". Vac. Sci. Technol. B, 18, (2000), pp1054-1058.

48. Kong, J., Soh, H.T.S., Cassell, A., Quate, C.F. and Dai, H. "Synthesis of individual single-walled carbon nanotubes on patterned silicon wafers". Nature, 395, (1998), pp878-881.

49. Rosen, R., Simendinger, W., Debbault, C., Shimoda, H., Fleming, L., Stoner, B. and Zhou, O. "Application of carbon nanotubes as electrodes in gas discharge tubes". Appl. Phys. Letters, 76, (2000), pp1668-1670.

50. Murakami, H., Hirakawa, M., Tanaka, C. and Yamakawa, H. "Field emission from well-aligned, patterned, carbon nanotube emitters. Appl. Phys Letters, 76, (2000), pp1776-1778.

51. Nilsson, L., Groening, O., Emmenegger, C., Kuettel, O., Schaller, E., Schlapbach, L., Kind, H., Bonard, J.M. and Kern, K. "Scanning field emission from patterned carbon nanotube films". Appl. Phys Letters, 76, (2000), pp2071-2073.

52. Ding, R.G., Lu, G.Q., Yan, Z.F. and Wilson, M.A. "Recent Advances in the Preparation and Utilisation of Carbon Nanotubes for Hydrogen Storage", Journal of Nanoscience and Nanotechnology, 1, (2001), pp7-29.

53. Cole, M.W., Crespi, V.H., Stan, G., Ebner, C., Hartman, J.M., Moroni, S., Boninsegni, A. "Condensation of helium in nanotube bundles". Phys Rev.Letters, 84, (2000), pp3883-3886.

54. Ozaki, T., Iwasa, Y. and Mitani, T. "Stiffness of Single-Walled Carbon Nanotubes under Large Strain". Phys. Rev Letters, 84, (2000), pp1712-1715.

55.Dujardin, E., Ebbesen, T.W., Krishnan, A., Yianilos, P.N., Treacy, M.M.J. "Young's modulus of single-walled nanotubes". Phys Rev. B, 58, (1998), pp14013-14019.

56.Yu, M.F, Lourie, O., Dyer, M.J., Moloni, K., Kelly, T.F. and Ruoff, R.S. "Strength and breaking mechanism of multiwalled carbon nanotubes under tensile load". Science, 287, (2000), pp637-640.

57. Forro, L., Salvetat, J.P., Bonard ,J.M., Basca, R., Thomson, N.H., Garaj, S., Thien-Nga, L., Gaal, R., Kulik, A., Ruzicka, B., Degiorgi, L., Bachtold, A., Schonenberger, C., Pekker, S. and Hernadi, K., Science and Application of Nanotubes, Tomanek, D. and Enbody, R.J. (Eds), Kluwer Academic/ Plenum, Publishers, New York, (2000), pp297.

58.Poulin, P., Vigola, B., Penicaud, A., and Coulin, C., CRNS French Patent 0002272, (1999).

59. Baughman, R.H., Cui, C., Zakhidov, A.A., Iqbal, Z., Barisci, J.N., Spinks, G.M., Wallace, G.G., Mazzoldi A.,De Rossi D., Rinzler A.G., Jaschinski O., Rot S. and Kertesz M. “Carbon nanotube actuators”. Science, 284, (1999), pp13401344.

60. Drexler, K.E. "Molecular engineering: An approach to the development of general capabilities for molecular manipulation". Proceedings of the National Academy of Sciences USA, 78, (1981), pp5275-5278.

61. Drexler, K.E. Engines of Creation, Fourth Estate, London, (1990) pp296.

62. Cummings, J. and Zettl, A. "Low-friction nanoscale linear bearing realized from multiwall carbon nanotubes". Science, 289, (2000), pp602-604.

63. Wilson, M., Moy, A., Rose, H., Kannangara, K., Young, B., McCulloch, D. and Cockayne, D. "Fullerene blacks and cathode deposits derived from plasma arcing of graphite with naphthalene". Fuel, 59, (2000), pp47-56. 


\section{PUBLICATIONS}
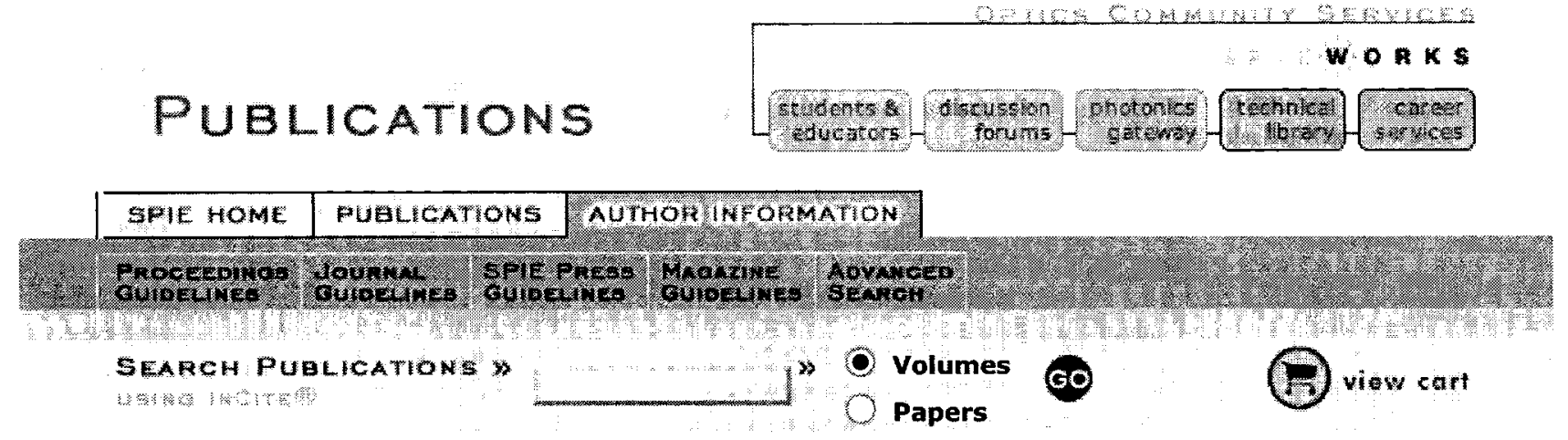

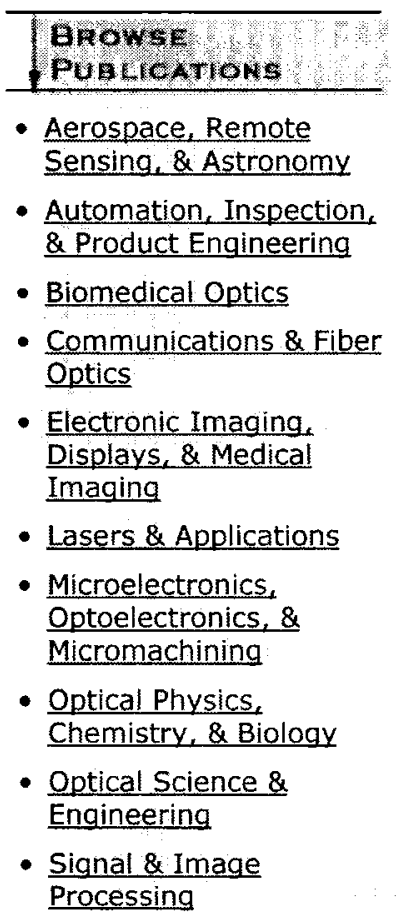

\section{Author Information} PUBLICATIONS

SPIE provides a variety of publishing opportunities for academic and industry professionals in optics, imaging, photonics, and optoelectronics.

\section{Proceedings of SPIE}

SPIE publishes full-manuscript proceedings of technical conferences sponsored or cosponsored by the Society. SPIE conferences are organized to provide live presentation of reports on current research resulting in proceedings that accurately reflect those presentations.

Authors are expected to submit manuscripts containing original, previously unpublished work in accordance with their specific conference deadlines. All authors of oral and poster presentations must furnish manuscripts.

\section{SPIE PRESS}

The SPIE PRESS invites inquiries and book proposals from prospective authors of optics, imaging, photonics, and optoelectronic texts. The PRESS publishes peer-reviewed handbooks, reference books, tutorials, and reprint collections in four main series:

- Monographs \& Handbooks: Authoritative, professional reference books, textbooks, and handbooks.

- Tutorial Texts: Introductory and intermediate-level tutorials in optical science and engineering.

- Milestone Series: Selected reprints of key papers from the world literature.

- Critical Reviews: Invited review papers by leading researchers in optics and photonics.

\section{Journals}

SPIE publishes four technical journals with individual author guidelines:

- Optical Engineering Author Information

- Journal of Electronic Imaging Author Information (copublished with IS\&T)

- Journal of Biomedical Optics Author Information

- Journal of Microlithography, Microfabrication, \& Microsystems Author Information (beginning 2002)

\section{Magazines}

oemagazine invites inquiries to the editor-in-chief, Kristin Lewotsky, regarding technical articles, business news, and new products. The magazine plans its feature lineups six months out from date of publication. Please contact Kristin Lewotsky if you are making advances in a specific area that you would like to discuss in a feature, are developing a product of note, or would like to discuss a business trend that is affortinn voni nr unur nrnanisation

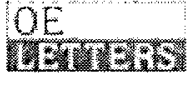

Newly Accepted Optical Engineering Letters

I Resources

- Conference Calendar

- Electronic Manuscript Submission 


\section{Comments on Paper 21354 Wilson et al}

It explores the liquefaction behaviour of a suite of Indonesian coals using the procedures developed in Professor Jacksons laboratory on Australian coals - the results are interpreted using the concepts also developed earlier by Jackson and coworkers on Australian coals.

\section{Abstract \\ This is the longest abstract I have ever read and really makes an excellent conclusion section rather than an abstract. In fact it is pretty hard to distinguish it from the actual conclusion.}

\section{Literature Review}

This is appropriate and to the point. It concentrates on catalysis from p3 onwards and summarises the importance of solvent and catalyst on liquification yields.

It is important if meaningful conclusions and comparisons are to be made between coals that the coal used are properly characterised. This has been done very well by chemical methods. However some descriptive information on petrology and in particular geological setting would have assisted the reader. At a Gordon conference the late Professor Given, one of the worlds most famous coal scientists once said " no two coals reach the same rank by the same process" to which Professor Frank Derbyshire (recently deceased) replied "therefore no two coals reach the same rank". The point here is that geology is most important together with the original organic matter in determining a coals synthesis. While full chemical characterisation is vital it is worth getting all the other information that is known in place for a thorough description.

\section{Product Analysis}

A little more care should have been taken in the Tables. Some of the ratios are incorrect see manuscript

I appreciated the inclusion of appendix sections which made reading of the thesis less arduous.

\section{Summary}

The paper demonstrates a clear understanding of the literature, a thorough knowledge of the field and techniques used and a significant contribution to knowledge. There is a large body of new data, which has been appropriately interpreted in terms of current theory. 


\section{PROCEEDINGS OF SPIE REPRINT}

(19. SPIE-The International Society for Optical Engineering

Reprinted from

\section{Device and Process Technologies for MEMS and Microelectronics II}

17-19 December 2001

Adelaide, Australia

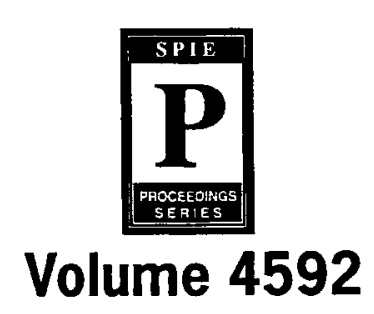

